\title{
Sistem Keamanan Rumah Berbasis Raspberry Pi dan Menggunakan Sensor PIR
}

\author{
B udhi Sumboro*1, Sutariyani ${ }^{2}$, Ronny Imam Utomo ${ }^{3}$ \\ ${ }^{1,2}$ Program Studi Sistem Informasi, STMIK AUB, Surakarta, Indonesia \\ ${ }^{3}$ Program Studi Sistem Komputer, STMIK AUB, Surakarta, Indonesia \\ e-mail: *1 budhi.sumboro@stmik-aub.ac.id,'tari.yani@stmik-aub.ac.id, \\ ${ }^{3}$ ronnysoekamti99@gmail.com
}

\begin{abstract}
Abstrak
Tindak kejahatan tidak dapat dipisahkan dari kehidupan sehari-hari karena sebuah aksi kejahatan dapat dilakukan kapan saja dan dimana saja, salah satunya aksi pencurian didalam rumah. Saat adanya wabah Covid-19 tingkat kriminalitas di Indonesia meningkat, sebesar 7,04 persen, pada pekan ke-19 terjadi 3.481 kasus kemudian di pekan ke-20 naik menjadi 3.726 kasus kejahatan. Keadaan seperti ini akan membuat seseorang mengalami kesulitan dalammengawasi keadaan rumah.

Tujuan penelitian ini untuk merancang dan membangun sistem keamanan ru mah agar dapat mengawasi atau memonitoring keadaan rumah saat ditingalkan. Maka dilakukanlah penelitian yaitu membangun sistem keamanan rumah dengan menggunakan metode Waterfall. Sistem keamanan ini dilengkapi dengan sensor PIR untuk mendeteksi adanya gerakan, setelah mendeteksi adanya gerakan Raspberry Pi memerintahkan mo dul kamera untuk mengambil gambar dan mengirimkan ke API Telegram dilanjutkan ke Aplika si Telegram, saat gambar terkirim Raspberry Pi membunyikan speaker sebagai alarm peringatan. Pengguna bisa melakukan perintah ke Raspberry Pi untuk mengambil gambar atau video. Jarak maksimal dari sensor PIR adalah 5 meter sehingga jika objek berada di kejauhan lebih dari 5 meter sensor PIR tidak dapatmendeteksi adanya pergerakan, dan sudut sensitivitas dari sensor PIR dapat bekerja pada sudut $45^{\circ}$ sampai $135^{\circ}$.
\end{abstract}

Kata kunci-Sistem Keamanan Rumah, Raspberry Pi, Sensor PIR

\begin{abstract}
Crime cannot be separated from everyday life because of a crime can be done a nytime and anywhere, one of which is an action theft in the house. During the Covid-19 outbreak, the crime rate was at Indonesia increased, by 7.04 percent, in the 19th week there were 3,481 cases then in the 20th week increased to 3,726 crime cases. Circumstances like this will make someone have difficulty monitoring the state of the house.

The purpose of this research is to design and build a home security system in order to supervise or monitor the condition of the house when it is left. So a research was conducted, namely building a home security system using the Waterfall method. This security system is equipped with a PIR sensor to detect movement. After detecting movement, the Raspberry Pi orders the camera module to take a picture and send it to the Telegram API and continue to the Telegram application, when the image is sent the Raspberry Pi sounds the speaker as a warning alarm. Users can do commands to the Raspberry Pi to take pictures or videos. The maximum distance from the PIR sensor is 5 meters so that if the object is more than 5 meters away, the PIR sensor cannot detect any movement, and the sensitivity angle of the PIR sensor can work at an angle of $45^{\circ}$ to $135^{\circ}$.
\end{abstract}

Received April 3, 2020; Revised April 13, 2020; Accepted June 17, 2020 
Keywords - Home Security Systems, Raspberry Pi, Sensor PIR

\section{PENDAHULUAN}

Keamanan rumah merupakan salah satu hal yang penting dalam kehidupan. Setiap manusia membutuhkan keamanan yang lebih seperti halnya kesehatan. Tindak kejahatan tidak dapat dipisahkan dalam kehidupan sehari-hari dikarenakan sebuah aksi kejahatan dapat terjadi kapan saja dan dimana saja ketika pelaku memiliki kesempatan, salah satunya seperti aksi pencurian didalam rumah (Mubarok, dkk. 2018). Pada saat adanya wabah Covid-19 ini banyak kota-kota menerapkan pembatasan sosial berskala besar (PSBB) demi keselamatan bersama, banyaknya pabrik atau tempat kerja yang ditutup sehingga banyak orang yang tidak bekerja. Hal itu berdampak meningkatkan kriminalitas tindak pencurian karena terpaksa mencuri demi membiayai biaya hidup. Tingkat kriminalitas di Indonesia meningkat selama masa pandemi covid-19, data statis kejahatan yang dicatat POLRI, pada mingu ke-19 dan ke-20 terjadi kenaikan sebesar 7,04 persen. Pada pekan ke-19 pandemi terjadi 3.481 kasus kemudian dipekan ke-20 naik 245 kasus menjadi 3.726 kasus kejahatan (Pryatama dan Yakub. 2020). Keadaan seperti ini akan membuat seseorang mengalami kesulitan dalam mengawasi keadaan rumah. Untuk mengatasi hal tersebut, diperlukan suatu keamanan yang setiap saat dapat memantau keadaan sekitar rumah agar terhindar dari tindakan kriminalitas pencurian. Dengan pengaplikasian sistem yang dirancang ini bisa menekan angka kriminalitas yang terjadi dimasyarakan khususnya tindak kejahatan pencurian.

Sistem keamanan ini memanfaatkan suatu perangkat sensor PIR yang dapat mendeteksi adanya suatu gerakan. Jika sensor PIR tersebut aktif, maka akan memicu modul camera untuk mengambil foto dan mengirimkan gambar tersebut kepada pemilik rumah melalui aplikasi telegram messenger dan membunyikan speaker. Sehingga jika terjadi hal-hal yang mencurigakan, pengguna dapat langsung menghubungi pihak berwajib.

\section{METODE PENELITIAN}

\subsection{Teknik Pengumpulan Data}

Metode pengumpulan data adalah teknik atau cara yang dilakukan oleh peneliti untuk mengumpulkan data. Metode pengumpulan data yang digunakan penulis antara lain:

a. Teknik Observasi

Melakukan pengamatan secara langsung di lokasi penelitian terhadap obyek yang akan diteliti dan dibahas serta mengumpulkan data atau informasi sebanyak mungkin yang berhubungan dengan masalah yang diteliti.

b. Teknik Wawancara

Teknik pengumpulan data dengan wawancara dapat dilakukan secara terstruktur maupun tidak terstruktur. Maka penulis melakukan wawancara dengan Bp. Maryadi selaku ketua Rt dusun jaten, kecamatan girimarto, kabupaten Wonogiri dengan pembahasan topik mengenai keamanan rumah.

c. Studi Literatur

Penulis mencari, membaca dan mempelajari referensi berupa jurnal dan buku-buku yang berhubungan dengan penelitian yang dilakukan tentang Raspberry P $i$, Sensor Pir, telegram messenger, dan sistem keamanan rumah.

\subsection{Tahap - Tahap Penelitian}

Prosedur pengembangan alat yang digunakan pada Sistem Keamanan Rumah Berbasis Raspberry Pi dan Menggunakan Sensor PIR menggunakan prosedur pengembangan metode 
Waterfall. Model ini melakukan pendekatan secara sistematis dan urut mulai dari level kebutuhan sistem lalu menuju ke tahap analisa kebutuhan, design, implementasi, testing, dan maintenance. Tahap - tahapan bisa dilihat sebagai berikut:

a. Analysist Kebutuhan

Pada tahapan ini peneliti mencari studi literatur untuk mendapat informasi sebanyakbanyaknya dari data dan alat elektronika yang berkaitan dengan sistem keamanan rumah. Pemilihan perangkat akan disesuaikan dengan kebutuhan dari sistem keamanan seperti RaspberryPi, sensor PIR, speaker serta kamera. Sistem dibuat untuk dapat memberikan informasi yang sedang terjadi di dalam rumah.

b. Design

Tahap ini peneliti melakukan perancangan alat terhadap solusi dari permasalahan yang ada di lingkungan sekitar yang berkaitan dengan Sistem Keamanan Rumah Berbasis Raspberry $P i$ dan Menggunakan Sensor PIR dengan menggunakan software Fritzing.

\section{c. Implementation}

Pada tahap ini setelah melakukan perancangan alat, peneliti membangun alat seperti pemasangan sensor PIR, pemasangan modul kamera dan pemasangan speaker. Penulisan program dibuat dengan bahasa pemrogaman Bahasa Python 3.0 dan menggunakan software Putty.

\section{d. Testing}

Pada tahap pengujian ini, agar dapat mengetahui alat berfungsi dengan baik dengan cara menguji sensor PIR, modul kamera dan speaker. Apabila sensor PIR mendeteksi gerakan maka kamera langsung mengambil gambar dan speaker berbunyi.

\section{e. Maintenance}

Beberapa permasalahan yang ditemukan seperti Raspberry $P i$ tidak bisa terhubung dengan Telegram Messenger, kamera tidak bisa mengambil gambar, speaker tidak berbunyi, atau dari jaringan yang digunakan. Semua permasalahan yang telah didapatkan selanjutnya akan dilakukan perbaikan terus menerus agar sintem yang dibangun sesuai dengan yang diharapkan.

\subsection{Analisa Perangkat Keras}

Tabel 1. Kebutuhan Perangkat Keras

\begin{tabular}{|c|l|l|l|}
\hline No. & Device Name & Specification & Jumlah \\
\hline 1 & Raspberry Pi & $\begin{array}{l}\text { versi 3 model B, terdapat } \\
\text { port USB, Port HDMI, CSI } \\
\text { Port }\end{array}$ & 1 Pcs \\
\hline 2 & Sensor PIR & $\begin{array}{l}\text { Digunakan untuk } \\
\text { mendeteksi adanya gerakan }\end{array}$ & 1 Pcs \\
\hline 3 & $\begin{array}{l}\text { Module } \\
\text { Camera }\end{array}$ & $\begin{array}{l}\text { kamera 5 MP, kualitas } \\
\text { video 720p. }\end{array}$ & 1 Pcs \\
\hline 4 & Speaker & $\begin{array}{l}\text { Menggunakan batre 2 } \\
\text { AAA 1.5V }\end{array}$ & 1 pcs \\
\hline 5 & Micro SD & Tipe HC kapasitas 16GB & 1 Pcs \\
\hline 6 & Adaptor & $\begin{array}{l}\text { Model XBS-0530, Input } \\
100-240 \text { VAC, Output 5V- }\end{array}$ & 1 Pcs \\
---3 A & \\
\hline
\end{tabular}

\subsection{Analisa Perangkat Lunak}

Tabel 2. Kebutuhan Perangkat Lunak

\begin{tabular}{|c|l|l|l|}
\hline No & Nama Perangkat & Spe sifikasi & Jumlah \\
\hline 1 & Putty & $\begin{array}{l}\text { Mendukung SSH } \text { client, } \\
\text { telnet dan SFTP } \text { client }\end{array}$ & 1 Pcs \\
\hline
\end{tabular}




\begin{tabular}{|c|l|l|l|}
\hline 2 & $\begin{array}{l}\text { Telegram } \\
\text { Messenger }\end{array}$ & Versi 7.0 & 1 Pcs \\
\hline 3 & Python & Versi 3.0 & 1 Pcs \\
\hline
\end{tabular}

\subsection{Cara Kerja Sistem}

Cara kerja Sistem Keamanan Rumah ini telah dijelaskan pada diagram block. Saat program Raspberry Pi di jalankan otomatis menghubungkan ke Wifi dan sensor PIR menerima suatu gerakan maka sensor pir akan mengirimkan informasi bahwa ada suatu pergerakan pada Raspberry Pi. Raspberry kemudian memerintahkan kamera untuk mengambil gambar sebanyak 2 kali dan akan membunyikan speaker sebagai suara peringatan. Gambar yang diambil oleh kamera akan dikirimkan ke Api Telgram selanjutnya dikirim ke Telegram Messenger, pengguna telegram dapat memberikan trigger kepada Raspberry Pi untuk mengambil gambar atau video, seperti ditunjukkan di Gambar 1.

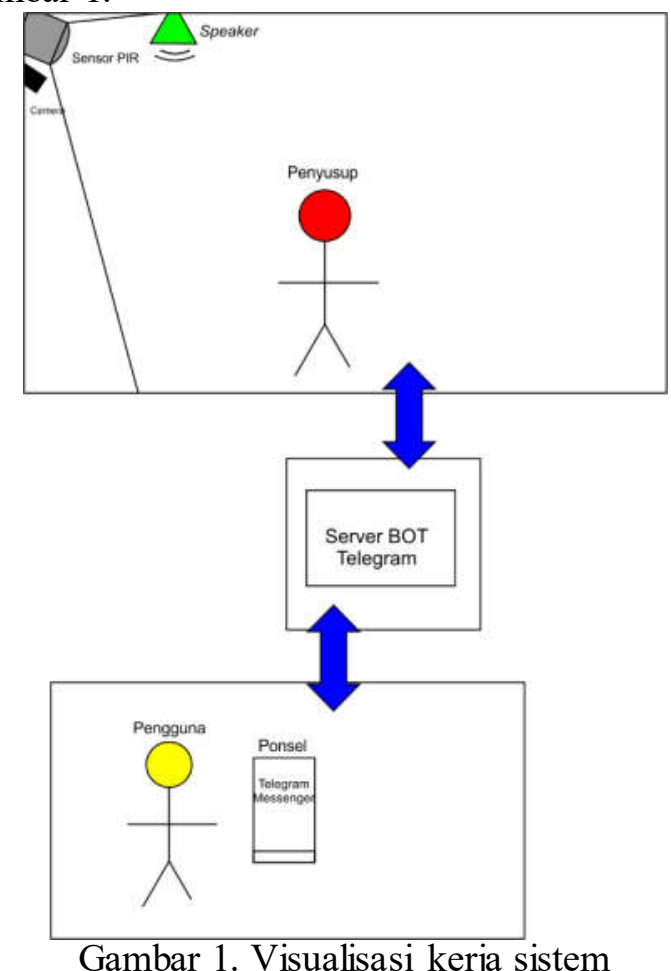

\subsection{Perancangan Sensor PIR}

Sensor PIR mempunyai 3 kaki dengan fungsi yang berbeda-beda diantaranya kaki 1 sebagai power $3-5 \mathrm{v}$, kaki 2 sebagai output, kaki 3 sebagai ground, kaki-kaki tersebut akan dihubugkan ke pin 5v, Ground, dan pin GPIO4 pada Raspberry Pi 3 Model B. Instalasi sensor PIR pada Raspberry Pi 3 model B dapat dilihat pada Gambar 2. 


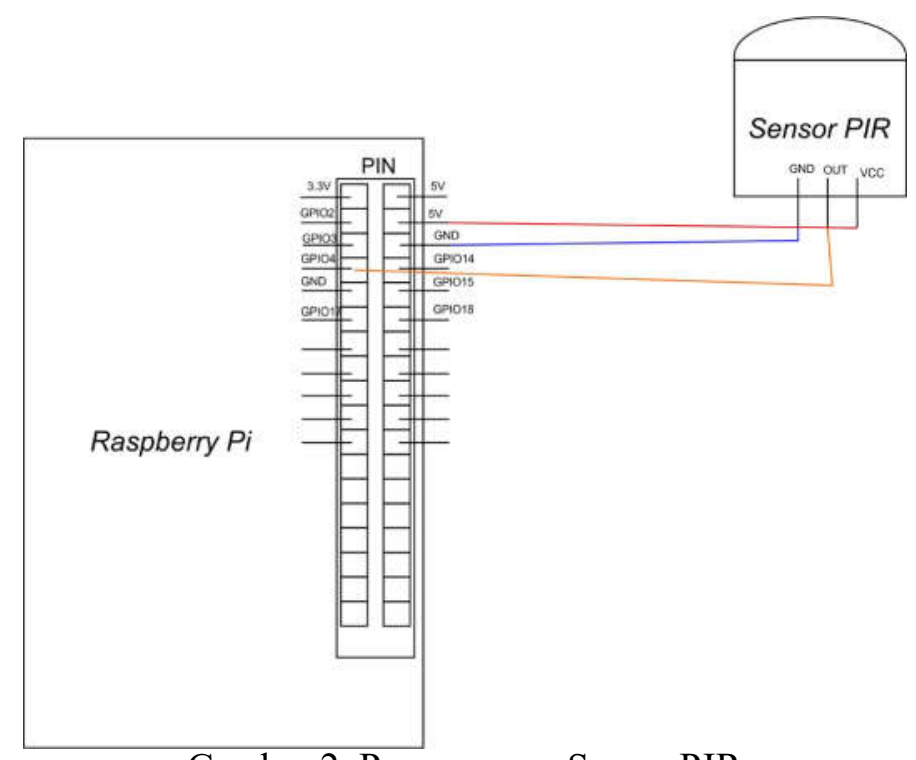

Gambar 2. Perancangan Sensor PIR

\subsection{Perancangan Module Camera}

Module kamera dengan resolusi 5 MegaPixel dan dapat mengambil video dengan resolusi 720p sampai 1080p. Kabel fleksibel pada modul kamera ini akan dihubungkan ke port CSI pada Raspberry Pi. Instalasi module kamera pada Raspberry Pi 3 model B dapat dilihat pada Gambar 3.

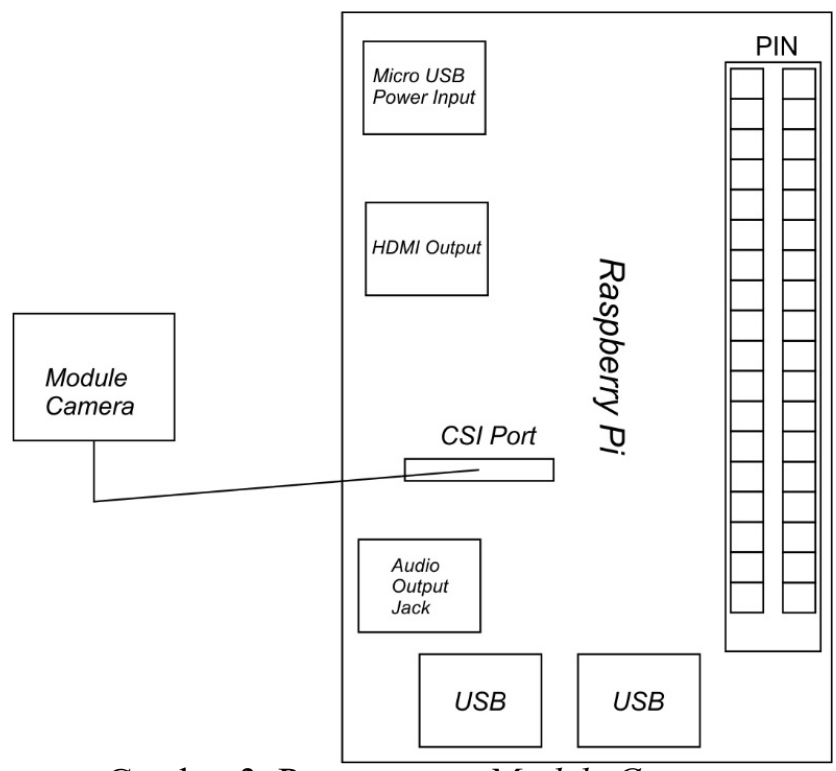

\subsection{Perancangan Speaker}

Gambar 3. Perancangan Module Camera

Speaker dihubungkan dengan jack audio yang sudah diseediakan oleh Raspberry Pi. Instalasi speaker pada Raspberry Pi 3 model B dapat dilihat pada Gambar 4. 


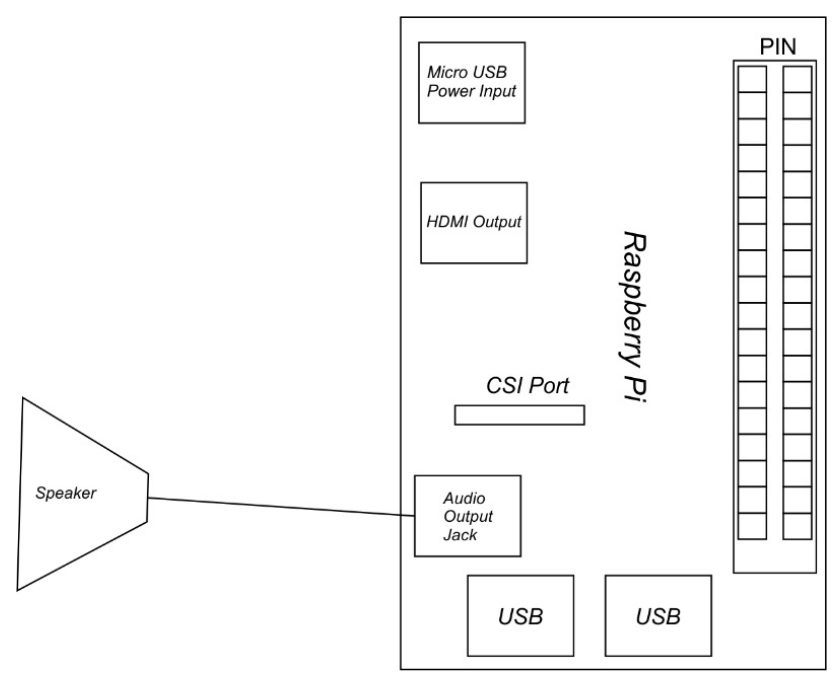

Gambar 4. Perancangan Speaker

\section{HASIL DAN PEMBAHASAN}

\subsection{Pengujian Alat}

Pengujian alat dilakukan dengan menguji sensor PIR.

a. Pengujian jarak jangkauan sensor PIR

Pengujian ini mengukur seberapa jauh sensor PIR dapat bekerja untuk mendeteksi gerakan. Dilakukan 5 kali percobaan pada setiap jarak yang telah ditentukan untuk menguji sensitivitas sensor PIR. Hasil dari pengujian sensor PIR berdasarkan jarak dapat dilihat pada Tabel 3.

Tabel 3. Pengujian Jarak Sensor PIR

\begin{tabular}{|c|c|c|c|c|c|c|}
\hline \multirow{2}{*}{$\begin{array}{l}\text { Jarak } \\
\text { (Meter) }\end{array}$} & \multicolumn{5}{|c|}{ Hasil Pengujian } & \multirow{2}{*}{$\begin{array}{l}\text { Persentase } \\
\text { Ke berhasilan }\end{array}$} \\
\hline & 1 & 2 & 3 & 4 & 5 & \\
\hline 1 & $\bar{B}$ & $\bar{B}$ & $\bar{B}$ & $\mathrm{~B}$ & $\bar{B}$ & $100 \%$ \\
\hline 2 & $\bar{B}$ & $\mathrm{~B}$ & $\bar{B}$ & $\mathrm{~B}$ & $\mathrm{~B}$ & $100 \%$ \\
\hline 3 & $\bar{B}$ & $\mathrm{~B}$ & $\mathrm{~B}$ & $\mathrm{~B}$ & $\mathrm{~B}$ & $100 \%$ \\
\hline 4 & $\mathrm{~B}$ & $\mathrm{~B}$ & $\mathrm{~B}$ & $\mathrm{~B}$ & $\mathrm{~B}$ & $100 \%$ \\
\hline 5 & $\mathrm{~B}$ & $\mathrm{G}$ & $\mathrm{G}$ & $\mathrm{B}$ & $\mathrm{B}$ & $70 \%$ \\
\hline 6 & $\mathrm{G}$ & $\mathrm{G}$ & $\mathrm{G}$ & $\mathrm{G}$ & $\mathrm{G}$ & $0 \%$ \\
\hline
\end{tabular}

$$
\begin{aligned}
& \text { Keterangan: } \\
& \text { B : Berhasil } \\
& \text { G : Gagal }
\end{aligned}
$$

b. Pengujian Sudut Sensor PIR

Pengujian ini dilakukan untuk mengetahui sudut optimum dari sensor PIR dalam mendeteksi gerakan secara horizontal dan vertikal. Hasil dari pengujian sensor PIR berdasarkan jarak dapat dilihat pada Tabel 4.

Tabel 4. Hasil Pengujian Sudut Sensor PIR

\begin{tabular}{|l|l|}
\hline \multicolumn{1}{|c|}{ Sudut Pos isi Objek } & \multicolumn{1}{c|}{ Hasil Pengujian } \\
\hline $30^{\circ}$ & Tidak Terdeteksi \\
\hline $45^{\circ}$ & Terdeteksi \\
\hline $60^{\circ}$ & Terdeteksi \\
\hline $75^{\circ}$ & Terdeteksi \\
\hline $90^{\circ}$ & Terdeteksi \\
\hline $105^{\circ}$ & Terdeteksi \\
\hline $120^{\circ}$ & Terdeteksi \\
\hline
\end{tabular}

GO INFOTECH: JURNAL ILMIAH STMIK AUB Vol. 26, No. 1, Juni 2020: 96 - 106 


\begin{tabular}{|l|l|}
\hline $135^{\circ}$ & Terdeteksi \\
\hline $150^{\circ}$ & Tidak Terdeteksi \\
\hline
\end{tabular}

\subsection{Pengujian Seluruh Sistem}

Pengujian seluruh sistem dilakukan mulai dari sensor PIR untuk mendeteksi gerakan dan kamera untuk mengambil gambar atau vidio. Semua parameter yang didapatkan dari sensor akan diproses oleh raspberry menjadi peringatan dan foto keadaan rumah yang dikirim ke telegram pemilik rumah. Raspberry Pi berkomunikasi dengan bot Telegram Messenger untuk mengirim pesan, Telegram Messenger menerima pesan, pengguna dapat memberi perintaj untuk mengambil foto atau vidio.

a. Pengujian Telegram Dengan Sensor PIR

Sensor PIR mendeteksi suatu gerakan, maka module kamera akan mengambil gambar sebanyak 2 kali dan dikirimkan ke Telegram pemilik rumah seperti Gambar 5.

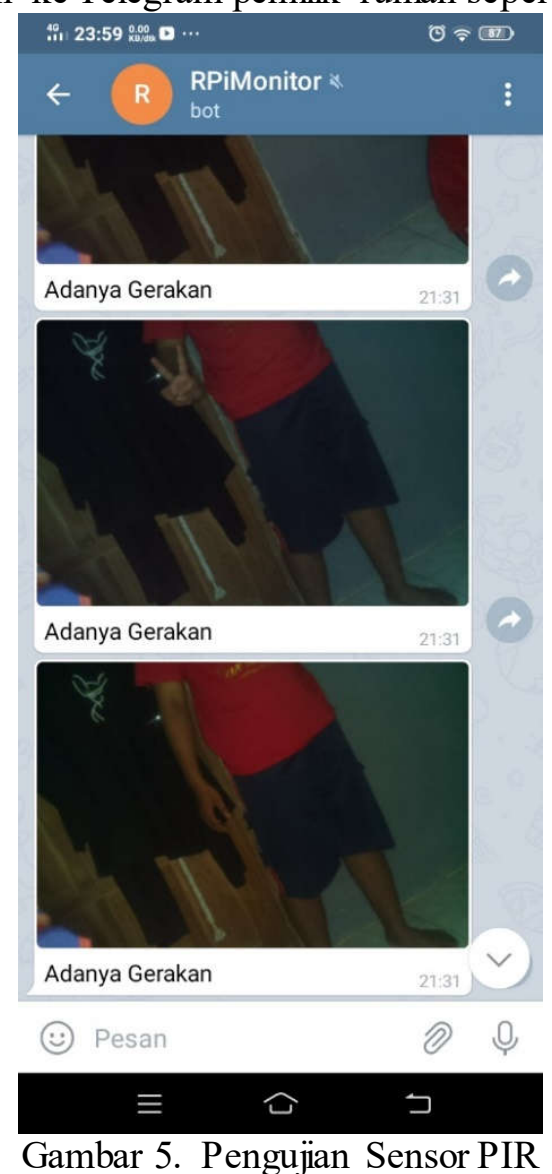

b. Pengujian Perintah Untuk Mengambil Gambar

Setelah mendapatkan informasi bahwa ada suatu gerakan maka pemilk rumah bisa memerintahkan Raspberry melalui Bot Telegram untuk mengambil gambar dengan perintah '/image' seperti Gambar 6. 


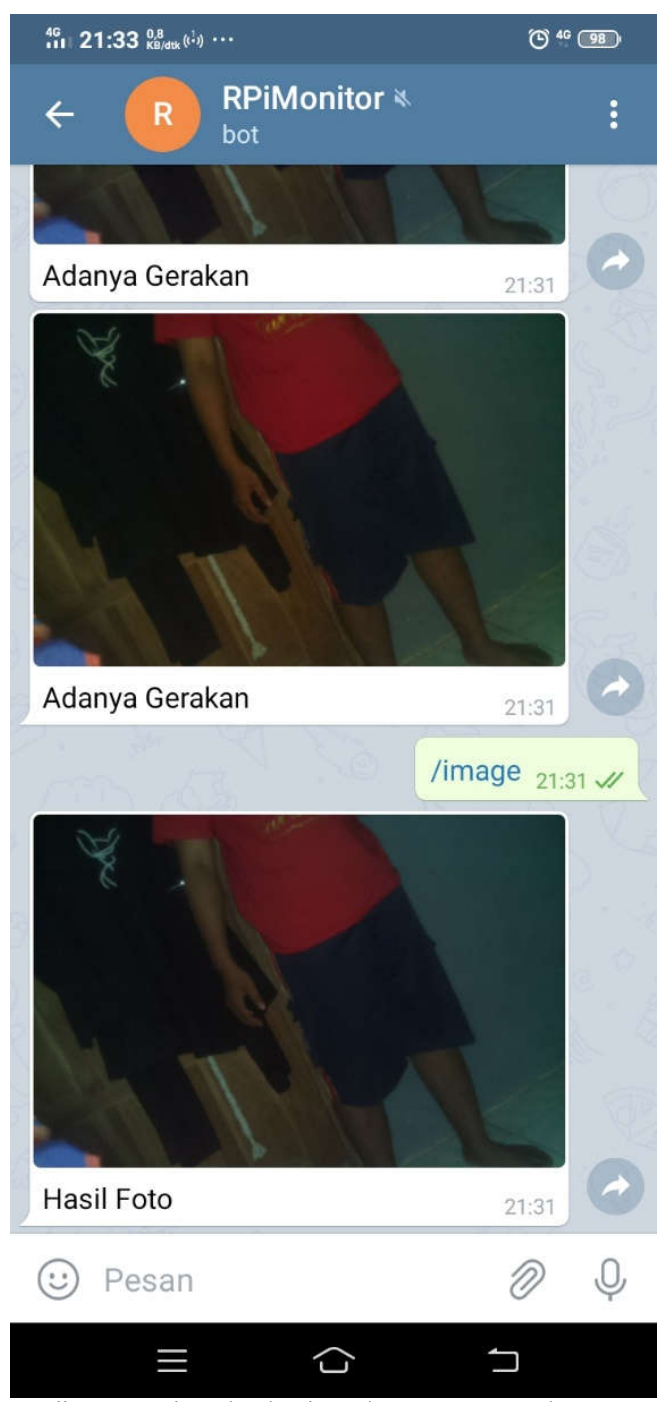

Gambar 6. Pengujian Perintah dari Telegram untuk Mengambil Gambar

c. Pengujian Untuk Mengambil Video

Pemilik rumah juga bisa memerintahkan untuk mengambil video dengan perintah '/video', vidio akan berhenti merekam jika mengirim perintah '/stop' sepertiGambar 7. 


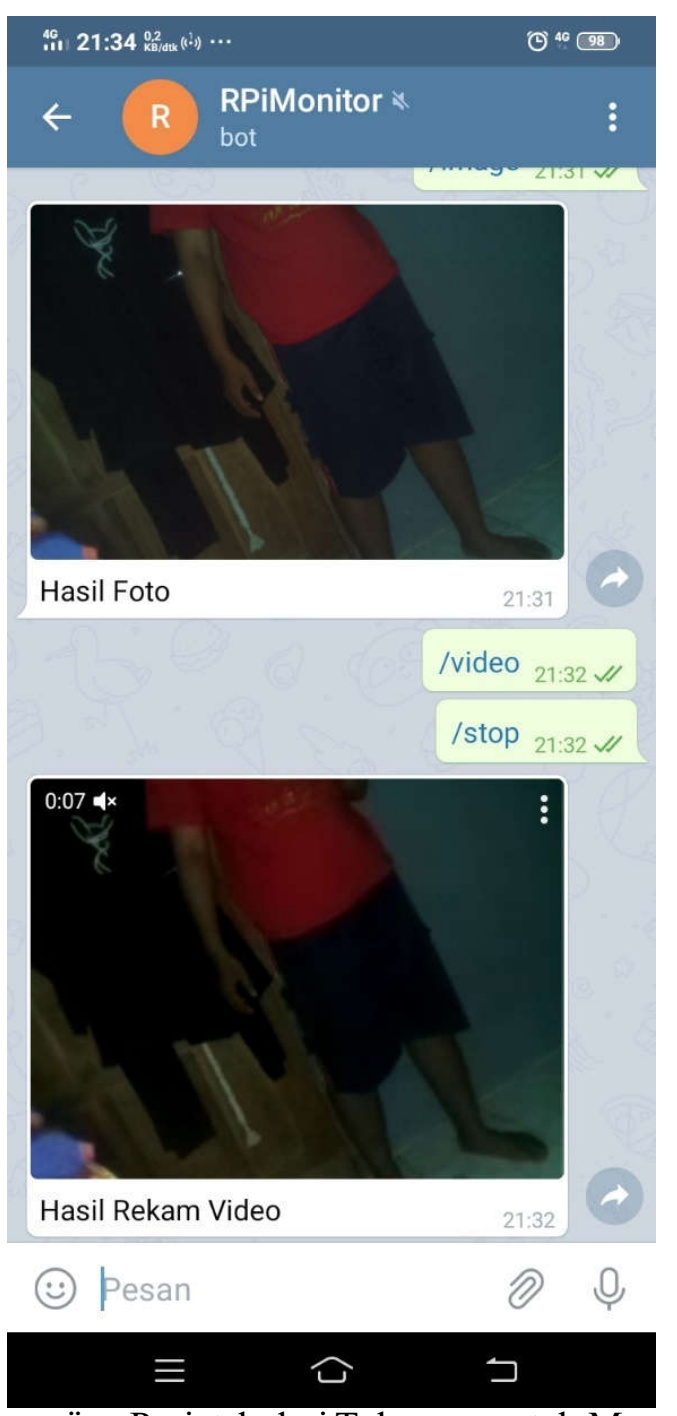

Gambar 7. Pengujian Perintah dari Telegram untuk Mengambil Video

\subsection{Pembahasan}

Tabel 5. Pembahasan Hasil Pengujian Seluruh Sistem Objek Sudut

\begin{tabular}{|c|c|c|c|c|c|c|}
\hline $\begin{array}{c}\text { Pengujian } \\
\text { ke }\end{array}$ & $\begin{array}{c}\text { Posisi } \\
\text { objek } \\
\text { Sudut }\end{array}$ & $\begin{array}{c}\text { Kondisi } \\
\text { sensor PIR }\end{array}$ & $\begin{array}{c}\text { Kondisi } \\
\text { Kamera }\end{array}$ & $\begin{array}{c}\text { Pes an } \\
\text { diterima }\end{array}$ & $\begin{array}{c}\text { Request } \\
\text { Foto }\end{array}$ & $\begin{array}{c}\text { Request } \\
\text { Video }\end{array}$ \\
\hline $\mathbf{1}$ & $30^{\circ}$ & $\begin{array}{l}\text { Tidak } \\
\text { Terdeteksi }\end{array}$ & Standby & Tidak & Berhasil & Berhasil \\
\hline $\mathbf{2}$ & $45^{\circ}$ & Terdeteksi & Aktif & Diterima & Berhasil & Berhasil \\
\hline $\mathbf{3}$ & $60^{\circ}$ & Terdeteksi & Aktif & Diterima & Berhasil & Berhasil \\
\hline $\mathbf{4}$ & $75^{\circ}$ & Terdeteksi & Aktif & Diterima & Berhasil & Berhasil \\
\hline $\mathbf{5}$ & $90^{\circ}$ & Terdeteksi & Aktif & Diterima & Berhasil & Berhasil \\
\hline $\mathbf{6}$ & $105^{\circ}$ & Terdeteksi & Aktif & Diterima & Berhasil & Berhasil \\
\hline
\end{tabular}




\begin{tabular}{|c|c|c|c|c|c|c|}
\hline $\mathbf{7}$ & $120^{\circ}$ & Terdeteksi & Aktif & Diterima & Berhasil & Berhasil \\
\hline $\mathbf{8}$ & $135^{\circ}$ & Terdeteksi & Aktif & Diterima & Berhasil & Berhasil \\
\hline $\mathbf{9}$ & $150^{\circ}$ & $\begin{array}{l}\text { Tidak } \\
\text { Terdeteksi }\end{array}$ & Standby & Diterima & Berhasil & Berhasil \\
\hline
\end{tabular}

\section{KESIMPULAN}

Pengujian sensor PIR mengetahui jarak maksimal sensor PIR dapat mendeteksiadanya suatu pergerakan objek adalah 5 meter. Artinya pada jarak yang lebih dari 5 meter objek akan gagal terdeteksi. Sudut sensitivitas sensor PIR dapat bekerja ketika posisi objek berada pada sudut $45^{\circ}$ sampai $135^{\circ}$. Diluar dari sudut $45^{\circ}$ sampai $135^{\circ}$ objek akan tidak terdeteksi. Sistem keamanan rumah berbasis Raspberry $P i$ ini bermanfaat bagi masyarakat untuk meningkatkan keamanan pada rumah.

\section{SARAN}

Untuk penelitian yang lebih lanjut dapat dibangun dengan menambahkan beberapa sensor untuk memonitoring rumah misalnya menambahkan sensor MQ-2 untuk mendeteksi adanya kebocoran gas, menambahkan sensor DHT11 untuk mengetahui suhu diruangan. Sistem ini belum bisa membedakan objek yang ditangkap oleh kamera sehingga ketika ada hewan atau benda yang melewati sensor PIR, kamera otomatis akan mengambil gambar. Pada penelitian selanjutnya diharapkan sistem bisa membedakan manusia, hewan maupun benda. Sehingga jika ada hewan melintas Raspberry tidak mengirim sebuah informasi terhadap pengguna bahwa tidak ada penyusup. Diharapkan juga pada penelitian selanjutnya bisa melakukan multi sensor dan kamera sehingga dapat memantau diberbagai sudut rumah.

\section{DAFTAR PUSTAKA}

[1] Arafat A. (2016). Sistem Pengamanan Pintu Rumah Berbasis Internet of Things (Io T) Dengan ESP8266. Technologia: Jurnal Ilmiah, 7(4).

[2] Arga. 2019. Pengertian dan Fungsi Adaptor. https://pintarelektro.com/fungsiadaptor/(diakses pada tanggal 31 Agustus 2020)

[3] Arifianto R. (2014). Pengertian Flowchart dan Jenis-Jenis nya. https://rahmatarifianto.wordpress.com/2014/11/20/pengertian-flowchart-dan-jenisjenisnya/ (diakses pada tanggal 29 Juli 2020)

[4] Ariski S. 2019. Pengertian, Fungsi dan Cara Menggunakan Bot Telegram. https://bukugue.com/apa-itu-telegram/(diakses pada tanggal 31 Agustus 2020)

[5] Fitri \& Reski K R. (2017). Penggunaan Bahasa Pemrograman Python Sebagai Pusat Kendali Pada Robot 10-D. ISBN: 978-602-72004-3-2.

[6] Juwitra Apsari R. (2018). Monitoring Keamanan Rumah dengan Menggunakan Mikrokontroler melalui Web. Jurnal Manajemen Informatika, 8(1).

[7] Mubarok A, Sofyan I, Rismayadi A A, \& Najiyah I. (2018). Sistem Keamanan Rumah Menggunakan RFID, Sensor PIR dan Modul GSM Berbasis Mikrokontroler. Jurnal Informatika, 5(1), 137-144.

[8] Perdana. 2019. Inilah Perbedaan Memori SD Card, mini SD, dann MicroSD. https://carisinyal.com/memori-sd-card/amp/(diakses pada tanggal 31 Agustus 2020)

[9] Permana E, \& Hidayat R. (2017). Rancang Bangun Sistem Keamanan Rumah Berbasis Sms Gateway Menggunakan Mikrokontroler. Jurnal Teknologi Informasi dan Komunikasi ISSN, 2252-4517. 
[10] Pramono B A, Hendrawan A, \& Daru A F. (2019). RASPBERRY PI DENGAN MODUL KAMERA DAN MOTION SENSOR SEBAGAI SOLUSI CCTV LAB FTIK UNIV. SEMARANG. Jurnal Pengembangan Rekayasa dan Teknologi, 14(1), 5-9.

[11] Pryatama W, Yakub. 2020. Lima Bulan Pandemi Covid-19, Kriminalitas Naik 7 Persen. https://mediaindonesia.com/read/detail/314036-lima-bulan-pandemi-covid-19kriminalitas-naik-7-persen (diakses pada tanggal 13 Agustus 2020)

[12] Rafiudin R. (2003). Panduan Membangun Jaringan Komputer Untuk Pemula. Jakarta: PT Elex Media Komputindo.

[13] Rahmat A S. 2018. Pengertian SDLC dan Macam-Macam Metode SDLC. https://rahmatagusblog.wordpress.com/2018/11/11/pengertian-sdlc-dan-macam-macammetode-sdlc/ (diakses pada tanggal 31 Agustus 2020)

[14] Ramadhan A S, \& Handoko, L. B. (2016). Rancang bangun sistem keamanan rumah berbasis arduino mega 2560. Techno. com, 15(2), 117-124.

[15] Sedayu A, Yuniarti E, \& Sanjaya E. (2018). Rancang Bangun Home Automation Berbasis Raspberry Pi 3 Model B dengan Interface Aprlikasi Media Sosial Telegram sebagai Kendali.Al-Fiziya: Journal of Materials Science, Geophysics, Instrumentation and Theoretical Physics, 1(2), 42-47.

[16] Supriyatno E., \& Siswanto S. (2016) Pemodelan Sistem Audio Secara Wireless Transmitter Menggunakan Laser Pointer. Jurnal Teknologi Elektro, 8(1).

[17] Sutiono. 2015. Kelebihan dan Kekurangan Metode Waterfall Dalam Pengembangan Sistem. https://dosenit.com/kuliah-it/teknologi-informasi/kelebihan-dan-kekuranganmetode-waterfall (diakses pada tanggal 31 Agustus 2020)

[18] Tempongbuka H., Allo E K., \& Sompie S R. (2015). Rancang Bangun Sistem Keamanan Rumah Menggunakan Sensor Pir (Passive Infrared) dan SMS Sebagai Notifikasi. Jurnal Teknik Elektro dan Komputer, 4(6), 10-15.

[19] Utomo D., Sholeh M., \& Avorizano A. (2017, November). Membangun Sistem Mobile Monitoring Keamanan Web Aplikasi Menggunakan Suricata dan Bot Telegram Channel. In Prosiding Seminar Nasional Teknoka (Vol. 2, pp. I81-I87). 